\title{
1 Natural Frequency Degradation and Permanent 2 Accumulated Rotation for Offshore Wind 3 Turbine Monopiles in Clay
}

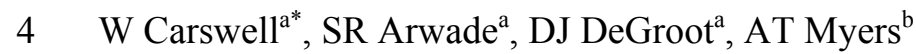

$5 \quad{ }^{a}$ Department of Civil \& Environmental Engineering, University of Massachusetts Amherst, 130 Natural

6 Resources Road, Amherst, MA 01003 USA

$7 \quad{ }^{\mathrm{b}}$ Department of Civil \& Environmental Engineering, Northeastern University, Boston, MA 02115 USA

$8 \quad$ *corresponding author. Email: wcarswel@umass.edu, Tel: (413) 545-0686

\begin{abstract}
9 Abstract
10 Offshore wind turbine (OWTs) monopile foundations are subjected to cyclic loading from wind, waves, 11 and operational loads from rotating blades. Lateral monopile capacity can be significantly affected by 12 cyclic loading, causing failure at cyclic load amplitudes lower than the failure load under monotonic 13 loading. For monopiles in clay, undrained clay behavior under short-term cyclic soil-pile loading (e.g. 14 extreme storm conditions) typically includes plastic soil deformation resulting from reductions in soil 15 modulus and undrained shear strength which occur as a function of pore pressure build-up. These impacts 16 affect the assessment of the ultimate and serviceability limit states of OWTs via natural frequency 17 degradation and accumulated permanent rotation at the mudline, respectively. This paper introduced 18 novel combinations of existing $p-y$ curve design methods and compared the impact of short-term cyclic 19 loading on monopiles in soft, medium, and stiff clay. The results of this paper indicate that short-term 20 cyclic loading from extreme storm conditions are unlikely to significantly affect natural frequency and 21 permanent accumulated rotation for OWT monopiles in stiff clays, but monopiles in soft clay may 22 experience significant degradation. Further consideration is required for medium clays, as load magnitude 23 played a strong role in both natural frequency and permanent rotation estimation.
\end{abstract}

\section{Keywords}

25 offshore wind turbines; monopiles; p-y curves; cyclic loading

\section{Nomenclature}

27 DE Delaware 


$\begin{array}{lll}28 & \text { MA } & \text { Massachusetts } \\ 29 & \text { NREL } & \text { National Renewable Energy Laboratory } \\ 30 & \text { OWT } & \text { Offshore wind turbine } \\ 31 & \text { SLS } & \text { Serviceability limit state } \\ 32 & \text { ULS } & \text { Ultimate limit state } \\ 33 & b & \text { Pile diameter } \\ 34 & g & \text { Acceleration due to gravity } \\ 35 & p & \text { Soil resistance } \\ 36 & p_{u} & \text { Ultimate soil resistance } \\ 37 & S_{u} & \text { Undrained shear strength } \\ 38 & t & \text { Wall thickness } \\ 39 & x & \text { Depth below mudline } \\ 40 & y & \text { Soil spring displacement } \\ 41 & y_{c} & \text { Soil spring displacement at } 50 \% \text { of ultimate soil resistance } \\ 42 & E & \text { Young's modulus } \\ 43 & H & \text { Horizontal mudline force } \\ 44 & H_{s} & \text { Significant wave height } \\ 45 & J & \text { Empirical factor } \\ 46 & K_{0} & \text { Initial spring stiffness } \\ 47 & K_{1} & \text { Initial spring stiffness for piecewise linear } p-y \text { curve } \\ 48 & K_{s e c} & \text { Secant spring stiffness } \\ 49 & M & \text { Mudline moment } \\ 50 & N & \text { Number of cycles } \\ 51 & T_{p} & \text { Peak spectral period } \\ 52 & U_{1-h r, h u b} & \text { One hour average wind speed at hub height } \\ 53 & \varepsilon_{c} & \text { Strain at } 50 \% \text { of undrained compression tests of undisturbed soil samples } \\ 54 & \gamma & \text { Submerged unit weight } \\ 55 & \lambda_{N} & \text { Degradation factor } \\ 56 & \rho & \text { Density of steel } \\ 57 & \sigma & \text { Standard deviation } \\ 58 & \xi & \text { Empirical coefficient } \\ & & \\ & & \end{array}$

\section{Introduction}

60 Offshore wind turbines (OWTs) are subjected to cyclic environmental loading from wind and waves and

61 cyclic operational loads from rotating blades. Most OWTs are supported by monopile foundations, which

62 account for more than $75 \%$ of currently installed OWT foundation systems [1,2]. Due to the lack of

63 redundancy in the design of a monopile and the nature of OWT loading, lateral soil capacity is one of the

64 primary limiting factors for the design of OWT monopile foundations. Lateral monopile capacity can be

65 significantly affected by cyclic loading, causing failure at a cyclic load amplitude lower than the failure

66 load under monotonic loading [3].

67 In terms of soil behavior, cyclic loading can be categorized into long-term or short-term loading: during 68 long-term cyclic loading, the pore pressure generated by cyclic loading dissipates and drained soil

69 behavior may be assumed; conversely, short-term cyclic loading leads to undissipated pore pressures 
which decrease effective stress and consequently reduce soil stiffness and undrained shear strength [4-6].

71 This issue is particularly of importance for clays, as the time for pore pressure to dissipate is typically much longer than for sands. Undrained clay behavior under short-term cyclic soil-pile loading typically includes plastic deformation of the soil (and subsequent gap formation at the pile head [5-8]), which comes from the reduction in soil modulus and undrained shear strength as a function of pore pressure build-up. This paper is focused on short-term cyclic loading of clays, a situation which arises for OWTs during storm conditions.

The impacts of short-term cyclic loading for monopiles in clay affect the assessment of both the ultimate limit state (ULS) and serviceability limit state (SLS) of OWTs. In the context of geotechnical design, the ULS of an OWT monopile is dictated by lateral soil-pile resistance, which is affected by cyclic loading. Reduction in soil-pile stiffness decreases the natural frequency of the entire OWT structure, causing the OWT natural frequency to shift towards the wave frequency spectra and to the frequency of a single OWT blade rotation (or 1P frequency). Under these circumstances, loads can be dynamically amplified and the simultaneous reduction of foundation capacity from cyclic loading and the amplification of loading can exceed the ULS of the soil. In terms of SLS, OWT monopiles are often designed to not exceed $0.5^{\circ}$ of tilt or rotation at the mudline (or other similar value as dictated by the turbine manufacturer). The $0.5^{\circ}$ threshold considered here consists of $0.25^{\circ}$ of construction tolerance and $0.25^{\circ}$ of permanent accumulated rotation [9]. This permanent accumulated rotation arises from inelastic soil behavior which is typically induced by cyclic wind and wave loads during the design life of the OWT [9]. In short, short-term cyclic loading of OWTs during storm conditions can induce two important and interactive effects: natural frequency degradation of the entire system and accumulated permanent rotation at the mudline. This paper considers both effects individually using novel combinations of existing design methods, since at present there is no consensus on a coherent design method for estimating either effect.

Laterally loaded OWT monopiles are usually designed and analyzed using the $p-y$ curve method [9], which represents soil-pile interaction as a series of nonlinear springs along the length of the pile. Because the experimental work to derive these curves was originally performed on small-diameter piles, many researchers have examined the discrepancy between predicted pile response from the $p-y$ method for large-diameter OWT monopiles and that which is predicted via finite element models or experimental modeling, e.g. [10-13]; however, the perceived complexity and computational expense of finite element models has prevented their widespread use, despite the increased accuracy of their constitutive models 
monopiles in clay subjected to cyclic lateral loading; however, in the absence of such a study, existing

103 cyclic $p-y$ curve models are used in this paper as a best estimate.

\section{Research Methodology}

105

106

107

108

109

110

111

112

113

114

115

116

117

This paper uses existing cyclic $p-y$ methods to examine two effects: natural frequency degradation and permanent accumulated mudline rotation for monopile-supported OWTs in clay. Regarding natural frequency degradation, a novel, hybrid approach is proposed using the static Matlock [14] $p-y$ curves determined by monotonic loading in conjunction with the ultimate soil resistance $\left(p_{u}\right)$ cyclic degradation model proposed by Rajashree \& Sundaravadivelu [15] as described in Section 3. Section 4 describes how rainflow counts of stochastic load time histories are used in conjunction with the established $p$-y methods to estimate the cumulative effect of cyclic degradation from a one-hour storm. An alternative, more generalized approach to cyclic degradation is introduced in Section 5, wherein the stiffness of $p-y$ springs within an embedment reduction zone is assumed to be negligible representing the effect of soil disturbance around the pile. The two hybrid methods for estimating natural frequency degradation (Section 6.2) and permanent mudline rotation (Section 6.3) are summarized schematically in Figure 1. The magnitude of permanent mudline rotations is predicted based on the unload-reload modulus proposed by [14] for cyclically loaded piles. In this paper, the soil-pile behavior is assumed to be elastic for $p-y$ springs with loading less than $0.5 p_{u}$ (half the ultimate resistance of the $p-y$ spring).

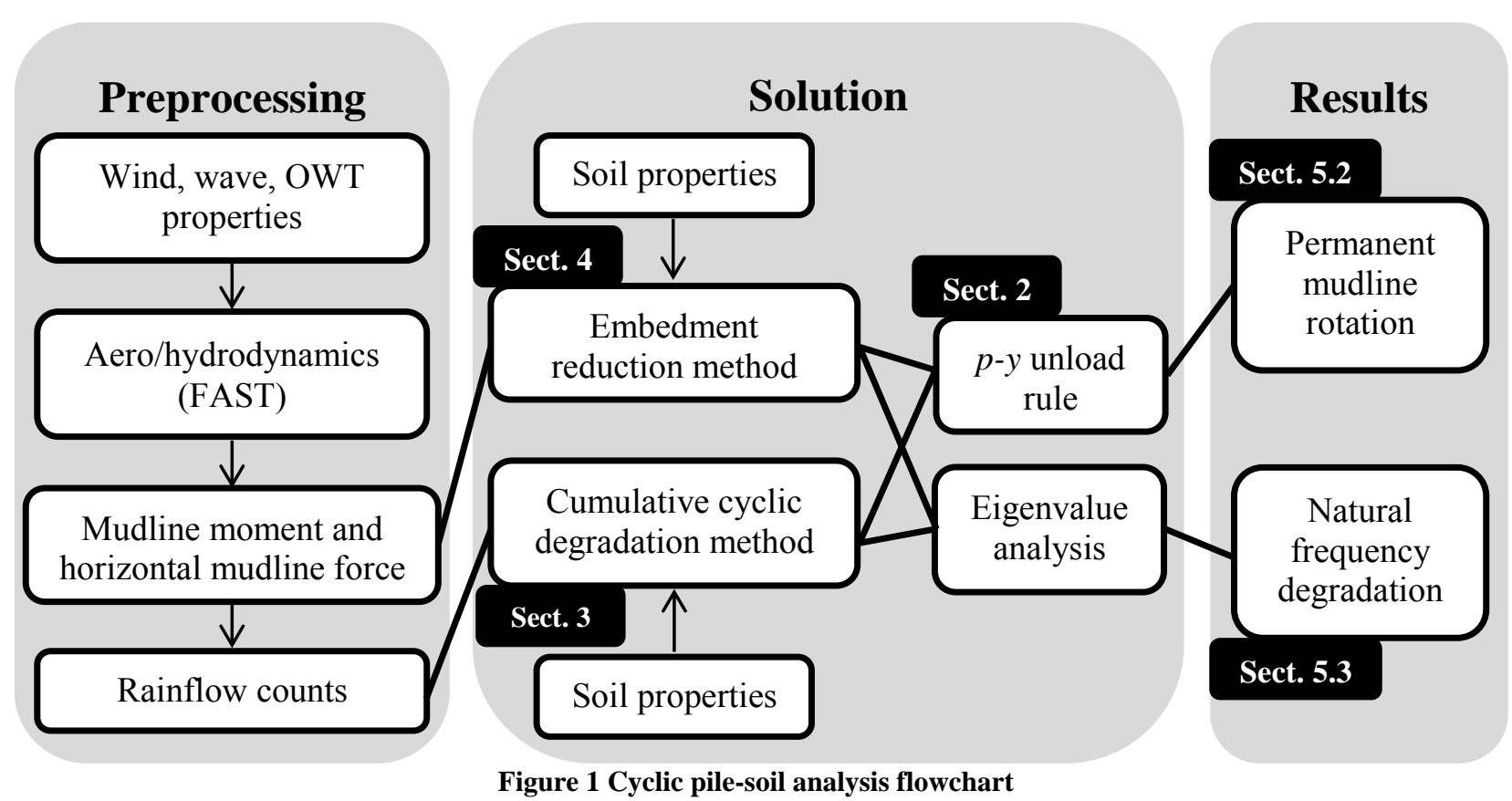


121 In Section 6, the effects of these two hybrid approaches are assessed for a range of conditions by

122 examining the frequency degradation and permanent accumulated rotation of the National Renewable

123 Energy Laboratory (NREL) 5MW Reference Turbine [16] supported by a monopile installed in

124 homogeneous deposits of soft, medium, and stiff clay. The turbine and monopile are modeled in FAST

125 [17] for extreme storm conditions representative of two different U.S. Atlantic offshore sites (off the

126 coasts of Massachusetts and Delaware). For both sites, storm conditions are assessed for multiple return

127 periods ranging from 50 to 500 years. While the extreme storm loading presented here may not represent

128 SLS loading in a traditional sense, the assessment of the SLS for monopiles should be performed for

129 loads which may cause permanent deformation of the soil [9]. The embedment reduction method and the

130 accumulated cyclic degradation method are compared for both natural frequency degradation and

131 permanent accumulated rotation, and the results of this paper show that only the largest load cycles during

132 extreme storms have significant impact on the natural frequency degradation or accumulated permanent

133 rotation.

\section{$134 \quad 3$ Existing Cyclic Models for Soil Stiffness and Strength}

135 This section discusses existing models for analyzing monopile foundations in clay subjected to cyclic

136 lateral loading. In most design situations, soil-pile interaction is considered through $p-y$ curves which

137 define the nonlinear relationship between lateral soil resistance $p$ and displacement $y$ along the length of

138 the pile. Det Norske Veritas [9] recommends the $p-y$ curves proposed by Matlock [14] for lateral soil-pile

139 resistance, though several other $p$-y models for clay exist (e.g. [7,18]). The American Petroleum Institute

140 (API) [19] recommends the $p$-y curves developed by Reese et al. [18] for stiff clays; however, research

141 performed by [7] indicated that the clay imbibed water during testing and therefore manifested more

142 degradation than other cases. For this reason, this paper uses the Matlock $p-y$ curve formulation for

143 monopiles in clay [9]. Further comparison of clay $p-y$ curves and behavior under cyclic degradation can

144 be found in [20].

145 The Matlock $p-y$ curves are currently recommended by design guidelines (e.g. DNV [9]) for the analysis 146 of laterally loaded OWT monopile foundations in clay, despite the fact that the curves were developed for 147 slender piles and OWT monopiles exhibit stiff pile behavior [10]. The $p-y$ curves are recommended 148 primarily for assessing the lateral response of the pile using a quasi-static load associated with the ULS.

149 Although Matlock has introduced a cyclic version of the $p-y$ curve [14], it is neither cycle nor amplitude 150 dependent [9], and provides only a lower bound on the soil-pile lateral stiffness. To overcome this 151 shortcoming in this paper, a quasi-static $p$-y degradation model by Rajashree \& Sundaravadivelu [15] is 152 used in conjunction with static/monotonic Matlock $p-y$ curves to explicitly account for the effects of both 
153 load amplitude and number of cycles on soil-pile behavior. This hybrid cyclic $p-y$ model is used for all

154 calculations presented in this paper.

155 The estimation of permanent accumulated rotations at the mudline requires an additional model to define 156 the elastic-plastic characteristics of the $p-y$ curves. The $p-y$ curves developed by Matlock [14] were based 157 on monotonic lateral load tests of slender, small diameter $(12.75 \mathrm{in}=0.32 \mathrm{~m})$ piles in soft, saturated clay. 158 In this paper, static $p-y$ curve behavior is assumed to be perfectly plastic after the lateral resistance $p$ 159 reaches the ultimate resistance $p_{u}$ with the full $p-y$ curve defined by

$$
p= \begin{cases}0.5 p_{u}\left(\frac{y}{y_{c}}\right)^{1 / 3} & \text { for } y \leq 8 y_{c} \\ p_{u} & \text { for } y>8 y_{c}\end{cases}
$$

160 where

$$
p_{u}=\left(3 s_{u}+\gamma^{\prime} x\right) b+J s_{u} x \leq 9 s_{u} b
$$

161 in which $s_{u}$ is the undrained shear strength, $\gamma^{\prime}$ is the submerged unit weight, $b$ is the pile diameter, $J$ is an 162 empirical factor ranging from 0.25 to 0.5 (for stiff to soft clays, respectively), and $x$ is the depth below 163 mudline. The depth at which $9 s_{u} b$ controls $p_{u}$ is referred to as the transition point, $x_{r}$. Spring displacement 164 is normalized by

$$
y_{c}=2.5 \varepsilon_{c} b
$$

165 where $\mathcal{E}_{c}$ is the strain occurring at one-half the maximum stress in laboratory undrained compression tests 166 of undisturbed soil samples.

167 Because clay $p-y$ curves have infinite initial stiffness, a finite estimate of initial stiffness is needed here to 168 estimate initial and degraded natural frequencies of the OWT system. Two finite initial stiffness estimates 169 are given in [9]; the first (denoted as $K_{0}$ here) is defined as

$$
K_{0}=\xi \frac{p_{u}}{b \varepsilon_{c}^{0.25}}
$$

170 where $\xi$ is an empirical coefficient equal to 10 for normally consolidated clay and 30 for overconsolidated 171 clay. If piecewise linear segments are used to represent the nonlinear $p$-y curves however, the 172 recommended endpoint of the first linearized segment is $p / p_{u}=0.23$ and $0.1 y_{c}$ [9], thereby making an 173 alternative estimation of the initial stiffness defined as 


$$
K_{1}=\frac{0.23 p_{u}}{0.1 y_{c}} .
$$

174 Permanent accumulated rotation after loading is assessed by assuming that soil springs unload elastically 175 following the nonlinear loading path of the $p-y$ curve for soil resistance $p<0.5 p_{u}$ and spring 176 displacements $y<y_{c}$ and linearly for $p>0.5 p_{u}$ and $y>y_{c}$; for inelastic soil springs in which $p>0.5 p_{u}$, the 177 unload/reload modulus of the springs is assumed to behave as proposed in [14]. It should be noted that 178 large mudline pile loads generally cause springs near the soil surface to load beyond the elastic range, 179 with increases in mudline loading causing progressively more soil springs along the length of the pile to 180 enter the inelastic range.

181 Both of initial stiffness estimates are shown in Figure 2, assuming $\xi=30$, along with a schematic 182 representation of the unload/reload modulus assumption from [14].

183

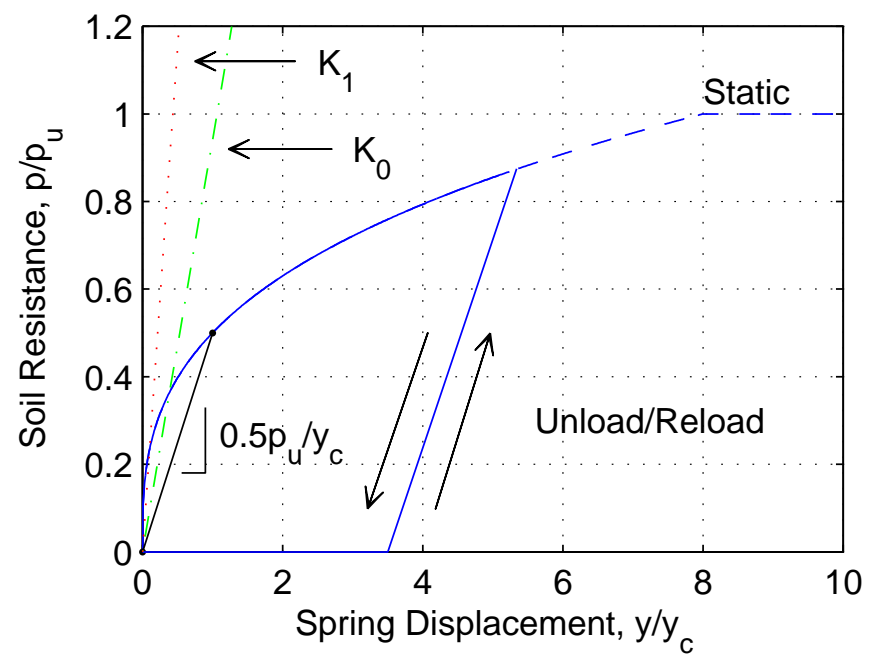

Figure 2 Static Matlock [14] p-y Curve with Cyclic Unload/Reload Modulus Assumption and Estimations of Initial Stiffness from [9].

The Rajashree \& Sundaravadivelu [15] p-y degradation model is used in conjunction with the static Matlock [14] $p-y$ curves to define soil-pile resistance as a function of load amplitude (via soil spring displacement) and number of cycles. The $p-y$ degradation model degrades the initial (first cycle) ultimate soil resistance $p_{u}$ to a degraded ultimate soil resistance $p_{u N}$ after a number of cycles $N$ by

$$
p_{u N}=\left(1-\lambda_{N}\right) p_{u}
$$

with degradation factor $\lambda_{N}$ defined as 


$$
\lambda_{N}=\frac{y_{1}}{0.2 b} \log (N) \leq 1
$$

191 in which $y_{1}$ is the displacement predicted by the static $p$-y curve and $b$ is the pile diameter. The 192 degradation method is therefore a function of the number of cycles and spring displacement (and 193 consequently also mudline load amplitude and corresponding pile-soil deformation shape), but is 194 independent of load frequency. Figure 3 demonstrates the degradation of a $p-y$ curve with 10 and 100 195 cycles of loading assuming an initial static displacement of $0.01 b$ and $0.05 b$. For a $6 \mathrm{~m}$ diameter pile, a 196 spring displacement of $0.05 \mathrm{~b}$ corresponds to $0.3 \mathrm{~m}$, which is relatively significant in the context of OWT monopile displacements given the mudline displacement design limitation of $0.2 \mathrm{~m}$ used by [21]. A spring displacement of $0.01 \mathrm{~b}$ corresponds to $0.06 \mathrm{~m}$ of spring displacement and as shown in Figure 3, approximately $5 \%$ degradation of the ultimate soil resistance $\left(p / p_{u} \approx 0.95\right)$.

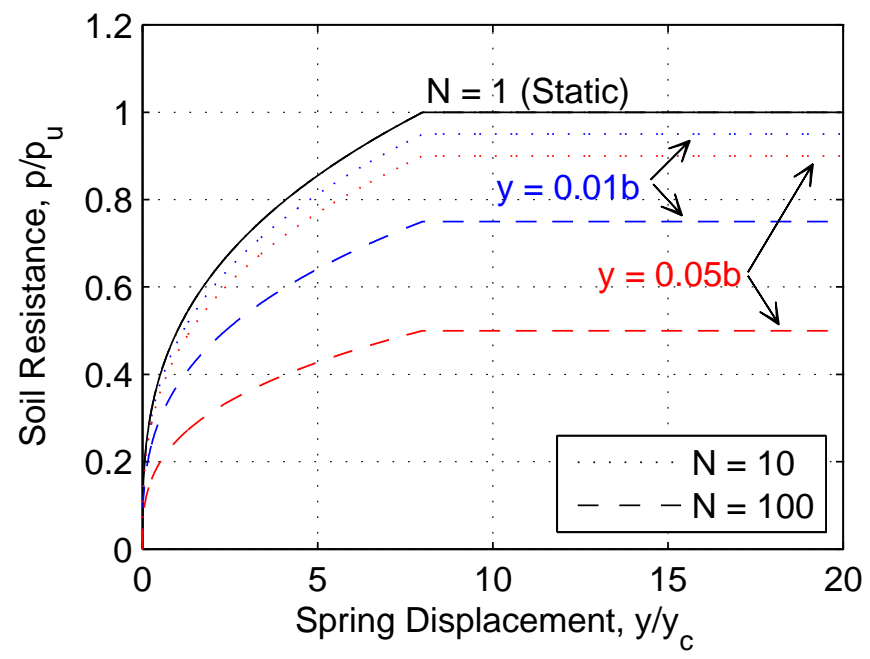

Figure 3 P-y Curve Degradation by Rajashree \& Sundaravadivelu [15]

202 This form of $p-y$ curve degradation compared favorably to one-way cyclic experimental testing of a small diameter pile $(25.4 \mathrm{~mm})$ in soft clay using the ultimate soil resistance relationship proposed by Matlock and for cyclic load magnitudes up to approximately $70 \%$ of the static lateral pile capacity [15]. It is assumed that the same caveats associated with the $p-y$ curves also apply to the hybrid Matlock-Rajashree $\&$ Sundaravadivelu degradation model proposed here.

\section{Cumulative Cyclic Degradation Model}

Because the $p-y$ method is recommended for ULS conditions, cyclic loading effects are typically taken into account using a quasi-static cyclic load amplitude and applied to a soil-pile system supported by $p-y$ curves modified to represent the lower bound resistance of a pile which has reached equilibrium under 
211 cycling [9,19]. Using this method assumes an infinite number of cycles at constant load amplitude, which

212 neglects the potential cumulative effects of varying load amplitudes from a storm time history.

213 In contrast, the cyclic accumulation method developed at the Norwegian Geotechnical Institute [3,22]

214 considers cumulative cyclic degradation for application to piles supported by $p-y$ curves, wherein cyclic

215 load histories (e.g. from extreme storm loading) are idealized using load parcels consisting of numbers of

216 load cycles at different load amplitudes. These load parcels are then applied in order of increasing load

217 amplitude using a cyclic accumulation/degradation method between each step to account for the

218 equivalent degradation from the number of load cycles $N$ associated with that load amplitude.

219 In the case of the NGI method, the cyclic accumulation method is applied in a three-dimensional finite 220 element model with the degradation of soil properties evaluated at each node using a custom constitutive 221 model informed by cyclic strain contour diagrams. While this consideration of cyclic accumulation is 222 likely a more accurate assessment of pore pressure accumulation and consequent cyclic degradation, the computational expense and complexity of the model are limiting factors.

224 A simplified cyclic degradation method is proposed in this paper based on a hybrid of static/monotonic $p$ $225 y$ curves [14] and $p-y$ curve degradation [15]. The process is as follows:

- Idealize storm load history into $i$ load parcels consisting of horizontal mudline force, mudline moment, and associated number of cycles $\left(H_{i}, M_{i}, N_{i}\right)$ using rainflow counting (Section 6.1).

- Find the static $p-y$ spring displacement associated with first load parcel $\left(H_{1}, M_{1}\right)$.

- Determine the ultimate soil resistance $p_{u, N 1}$ for each spring according to the $p$ - $y$ degradation model (Eqs. 6-7) using $N_{1}$ and the displacement associated with $\left(H_{1}, M_{1}\right)$.

- Load the degraded $p-y$ pile-spring model with $\left(H_{1}, M_{1}\right)$ and unload the degraded $p-y$ pile-spring model using the unloading rules described in Figure 1.

- Find the $p$ - $y$ spring displacement for the next load parcel $\left(H_{i+1}, M_{i+1}\right)$ using the current pile-spring model.

- Further degrade the ultimate soil resistance by $p_{u, N i+1}=\left(1-\lambda_{N i+1}\right) p_{u, N 1}$ for each spring using $N_{i+1}$ and the displacement associated with $\left(H_{i+1}, M_{i+1}\right)$.

- Load the degraded $p-y$ pile-spring model with $\left(H_{i+1}, M_{i+1}\right)$ and unload the degraded $p-y$ pilespring model.

- Repeat process for remainder of load parcels.

An example of this process is demonstrated in Figure 4 using a single $p$-y spring and three load parcels consisting of a lateral force only (no moment): (1) represents the static/monotonic initial $p-y$ curve which 
informs the degradation of the first load parcel; (2) illustrates the load-unload cycle for the first load parcel, which in this instance remains elastic; the $p-y$ curve associated with the first load parcel informs the degradation for the second load parcel; (3) denotes the peak of the second load parcel which exceeds the elastic limit and unloads linearly; (4) demonstrates the final permanent displacement after the third and final load parcel. It should also be noted that because degradation occurs between the second and third load parcels, the linear reloading of the third load parcel at (3) is at a different slope than the unloading branch of the second load parcel.

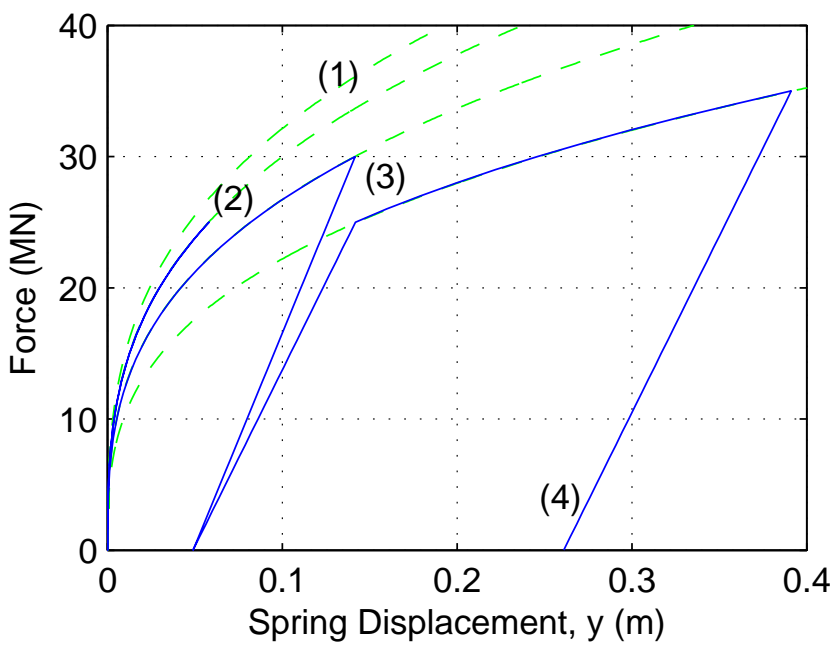

Figure 4 Single spring depiction of cumulative load effect from rainflow count degradation. Dashed lines represent degrading $p-y$ curves and solid lines represent the load-unload path of the single $p-y$ spring.

\section{$5 \quad$ Degradation via Embedment Depth Reduction}

The $p-y$ degradation model presented by Rajashree \& Sundaravadivelu [15] primarily degrades the strength of the soil rather than the stiffness. This section outlines an alternative method which explicitly reduces the embedment depth of the monopile to reflect the effects of the degradation of soil stiffness due to short-term cyclic loading. This method is motivated by observations of a zone of soil disturbance around the circumference of the pile in the natural frequency experimentation performed in [23], demonstrating inelastic soil behavior post-cycling with a significant amount of permanent monopile rotation. The disturbance of the soil around the perimeter of the pile may be indicative of gapping, which occurs when soil in the passive zone behind the pile is loaded beyond the linear range and residual soil displacements remain post-loading. Upon reloading, the pile travels freely through the gap before recontacting soil. This gapping behavior has been approached in a $p-y$ context using gap elements [24], but generally speaking it is a difficult behavior to characterize; moreover, in a linearized $p-y$ model (required 
264 for determining the natural frequency of the OWT via eigenvalue analysis), it is not clear how these gap

265 elements would contribute to soil-pile stiffness.

266 While the cumulative cyclic degradation model described in the previous section takes soil disturbance

267 into account implicitly, cyclic degradation could also be modeled more simply and explicitly in terms of 268 embedment reduction (Figure 5). This method assumes that there is no stiffness contribution from the $p-y$ 269 soil springs within a user-defined embedment reduction zone; in this paper, the results from embedment 270 reduction of $0.5 b$ and $1 b$ are presented to demonstrate a range of possible behavior.

271 Scour protection is a very important component of OWT monopile design [25] and the analysis of scour 272 is directly related to monopile embedment. Analysis of scour was considered outside the scope of this 273 paper; however, the embedment reduction method gives an indication of how erosion due to scour would 274 impact lateral soil-pile resistance and natural frequency estimation insofar as scour, gapping, significant 275 soil disturbance similarly result in the absence of soil at the top of the pile.

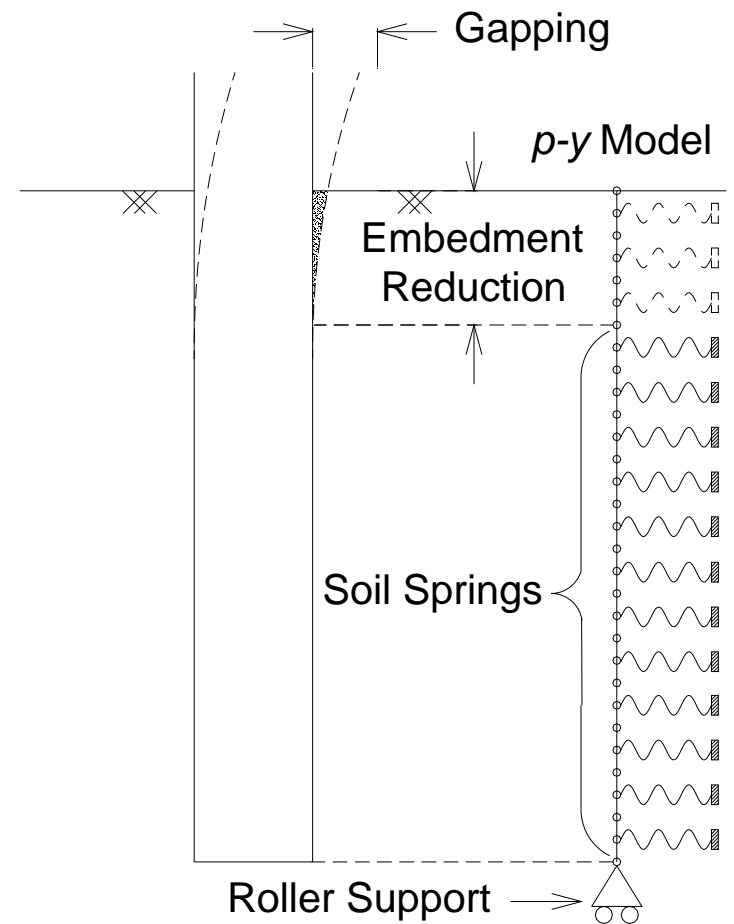

278 OWT natural frequency was calculated as a function of load level using $p$-y secant stiffness (Figure 6) and 279 including embedment reduction as follows: 
- Mudline loads $(H, M)$ were applied to the top of a $p-y$ pile-spring model, assuming pile springs in the embedment reduction zone contribute zero lateral stiffness.

- From the resulting displacement $y$ for each spring along the length of the pile, the soil resistance $p$ for each spring was determined from Eq. 1.

- The secant stiffness $K_{s e c}$ was then calculated as $p / y$.

- The natural frequency of the system was calculated via eigenvalue analysis.

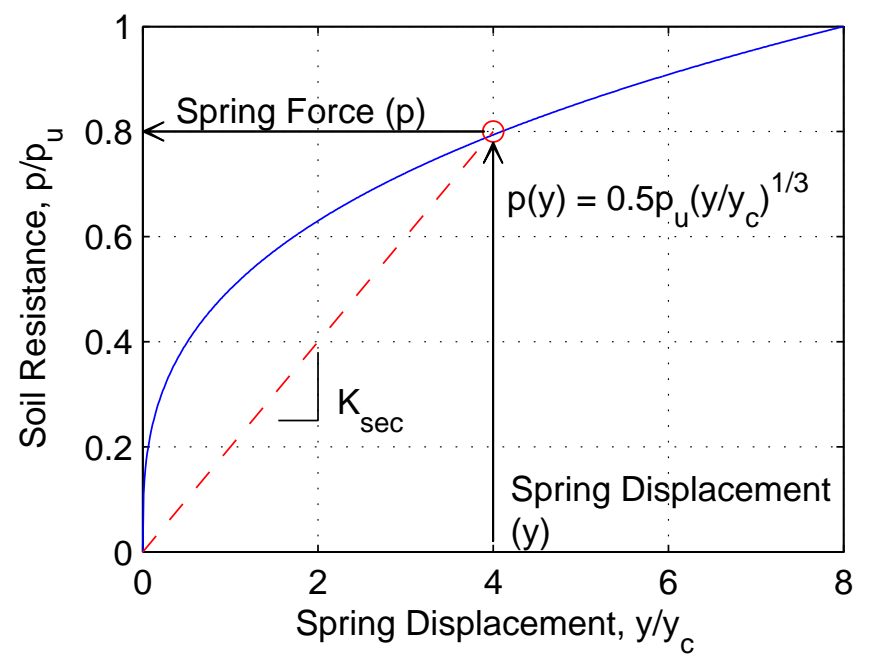

Figure 6 Determination of Secant Stiffness for Natural Frequency Degradation

\section{Application to the NREL 5MW Reference Turbine}

The effects of short-term cyclic loading are examined in this section for the NREL 5MW Reference Turbine supported by a $6 \mathrm{~m}$ diameter monopile embedded in clay (Figure 7). The NREL open-source wind turbine simulation program FAST [17] was used to calculate structural loads caused by one hour stochastic wind and wave time histories representative of the extreme storm for two locations off the U.S Atlantic coast. Two different approaches (Figure 1) are compared here for assessing OWT natural frequency and permanent accumulated pile rotation:

(1) The average maximum horizontal mudline force $(H)$ and mudline moment $(M)$ from the stochastic time histories is used with a $p-y$ curve pile-spring system including embedment reduction.

(2) Rainflow counts of the time histories were used to idealize the stochastic time histories into load parcels of $(H, M, N)$ and were used in conjunction with the cumulative cyclic degradation method proposed in Section 4. 
The pile design in this paper consists of a $6 \mathrm{~m}$ diameter pile with wall thickness of $0.09 \mathrm{~m}$ embedded 34 $\mathrm{m}$ into homogeneous clay with submerged unit weight of $9.2 \mathrm{kN} / \mathrm{m}^{3}$. A monopile of these dimensions is similar to the designs presented in literature (e.g. [26-28]). Three different undrained shear strengths are considered $(35 \mathrm{kPa}, 50 \mathrm{kPa}$, and $100 \mathrm{kPa})$ to examine the degradation and inelastic behavior of soft, medium, and stiff clays, as shear strength is the most influential property in $p-y$ curve formulation. In a true design context, the embedment depth of the piles would likely vary from site to site in order to approach fixity at the base of the pile (i.e., zero pile kick) and adequate force-displacement behavior over the range of expected loads; however, the focus of this paper is to examine the behavior which could occur as a function of soil properties and not to focus strictly on the behavior of the pile itself.

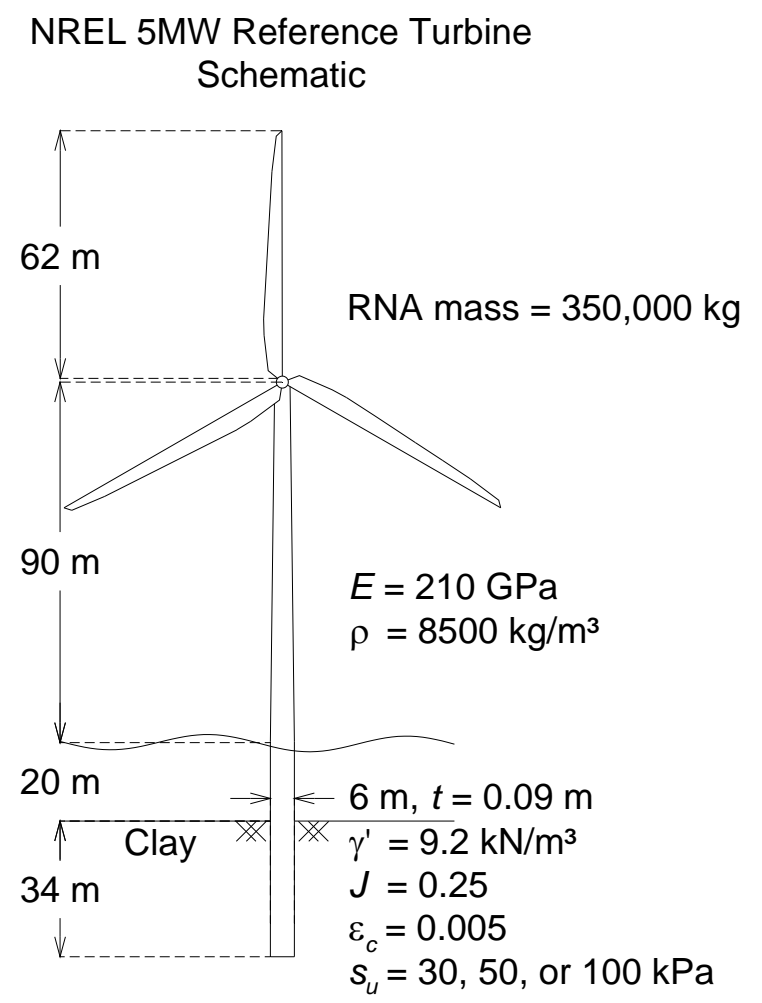

\section{$312 \quad 6.1$ Environmental Condition and Load Effect Models}

313 The 1-hr average wind speed at hub height $\left(U_{1-h r h u b}\right)$ and significant wave height $\left(H_{s}\right)$ from two sites were 314 considered in this study: a Massachusetts (MA) site between Martha's Vineyard and Block Island [29] 315 and the National Data Buoy Center (NDBC) buoy 44009 off the coast of Delaware (DE) [30]. Because 316 water depths for the MA and DE sites were $15 \mathrm{~m}$ and $30 \mathrm{~m}$ respectively, $H_{s}$ values were scaled linearly 317 for the NREL 5MW Reference Turbine model's $20 \mathrm{~m}$ water depth. While linearly scaling of $H_{s}$ may not 
result in exact physical representation of waves at different water depths, the waves generated by this

319 method are physically realistic and provide a plausible, illustrative example of extreme storm conditions

320 suitable for examining the degradation of soil-pile resistance.

321 The site conditions (Table 1) represent storm conditions for mean return periods between 50 and 500 322 years. In the case of the MA site, the 50- and 500-year conditions are taken from [29], using two methods 323 to estimate the 50-year conditions: 1) using data only from tropical storms and 2) from approximately 20 324 years of measured data. The site conditions for the DE site are calculated by the authors using 325 independent extreme value distributions fit to 30 years of annual maxima of wind and wave 326 measurements from the National Data Buoy Center [30].

327 The peak spectral period $T_{p}$ was calculated as a function of $H_{s}$ for extreme sea states [9] using

$$
T_{p}=11.1 \sqrt{H_{s} / g}
$$

where $g$ is the acceleration due to gravity, similar to the approach taken in [20,31]. The minimum estimate of $T_{p}$ is conservative, as smaller values of $T_{p}$ shift the wave frequency spectra closer to the natural frequency of the NREL 5MW Reference Turbine (thereby increasing dynamic loads) and also because smaller $T_{p}$ contributes to steeper waves and consequently greater particle velocity and acceleration.

Mudline loads for the NREL 5MW Reference Turbine were generated using NREL's aeroelastic code FAST [17] for the environmental site conditions in Table 1. Six 1-hr time histories per environmental site condition were simulated with a perfectly fixed mudline condition, $0^{\circ}$ yaw, co-directional wind and waves, and parked and feathered blades, similar to design load case 6.1a [9,32]. The average of the maximum horizontal mudline force and mudline moment from the six 1-hr time histories is denoted as $H_{\text {max,avg }}$ and $M_{\text {max,avg. }}$. Turbulent winds were generated according to the Kaimal spectrum assuming a turbulence intensity of 0.11 . Wind loads on the OWT blades were calculated using Blade Element Momentum (BEM) theory assuming a power law for vertical wind shear with an exponent of 0.14 . Linear irregular wave kinematics were generated using the JONSWAP spectrum and converted into wave loads using Morison's equation with $C_{m}$ and $C_{d}$ equal to 1.75 and 1.26 , respectively. The use of Morison's equation is valid when the diameter of the pile foundation is less than $20 \%$ of the wavelength [9]. Using the equations given in [9] to estimate the wavelengths of the site conditions in Table 1 as a function of water depth and wave period, the pile diameter ranges from approximately $3-6 \%$ of the wavelengths (estimated to be $100-175 \mathrm{~m}$ for a water depth of $30 \mathrm{~m}$ and wave periods from $8.5 \mathrm{~s}$ to $11.9 \mathrm{~s}$ ). 
Table 1 Environmental site conditions and load summary for NREL 5MW Reference Turbine in 20 m water depth

\begin{tabular}{|c|c|c|c|c|c|}
\hline Site & \multicolumn{3}{|c|}{ MA } & \multicolumn{2}{|c|}{ DE } \\
\hline Mean Return Period & 50 years & 50 years & 500 years & 50 years & 500 years \\
\hline $\begin{array}{c}\text { Wind-Wave Estimation } \\
\text { Method }\end{array}$ & $\begin{array}{l}\text { Tropical } \\
\text { Storm } \\
\end{array}$ & Measured & Measured & Measured & Measured \\
\hline$U_{1-h r, h u b}(\mathrm{~m} / \mathrm{s})$ & 47.6 & 38.1 & 42.2 & 32.8 & 37.4 \\
\hline$H_{s}(\mathbf{m})$ & 11.3 & 8.3 & 9.9 & 5.4 & 5.7 \\
\hline$T_{p}(\mathrm{~s})$ & 11.9 & 10.2 & 11.1 & 8.2 & 8.5 \\
\hline$H_{m a x, a v g}(\mathrm{MN})$ & 6.32 & 3.64 & 4.26 & 2.48 & 2.51 \\
\hline$\sigma_{\mathrm{H}, \text { avg }}(\mathrm{MN})$ & 1.12 & 0.861 & 1.00 & 0.618 & 0.633 \\
\hline$M_{m a x, a v g}(\mathrm{MNm})$ & 119 & 66.2 & 80.8 & 45.5 & 47.7 \\
\hline$\sigma_{M, a v g}(\mathrm{MNm})$ & 16.6 & 13.4 & 14.4 & 10.6 & 10.5 \\
\hline $\begin{array}{l}\text { Avg. Correlation } \\
\text { Coefficient }(H, M)\end{array}$ & 0.860 & 0.834 & 0.872 & 0.806 & 0.817 \\
\hline
\end{tabular}

349 It should be noted that the wave heights and periods shown in Table 1 may lead to breaking waves, but 350 the effects of these waves are neglected in this paper. Figure 8A shows an example of the time histories of $351 \quad H$ and $M$ from one 1-hr realization of the 50-year (storm) condition at the MA site. In Figure 8B, the assumption of $H$ and $M$ concurrence is further justified by the similar trends in the rainflow counts for all six 1-hr realizations of the time histories from the storm-based 50-year conditions at the MA site.
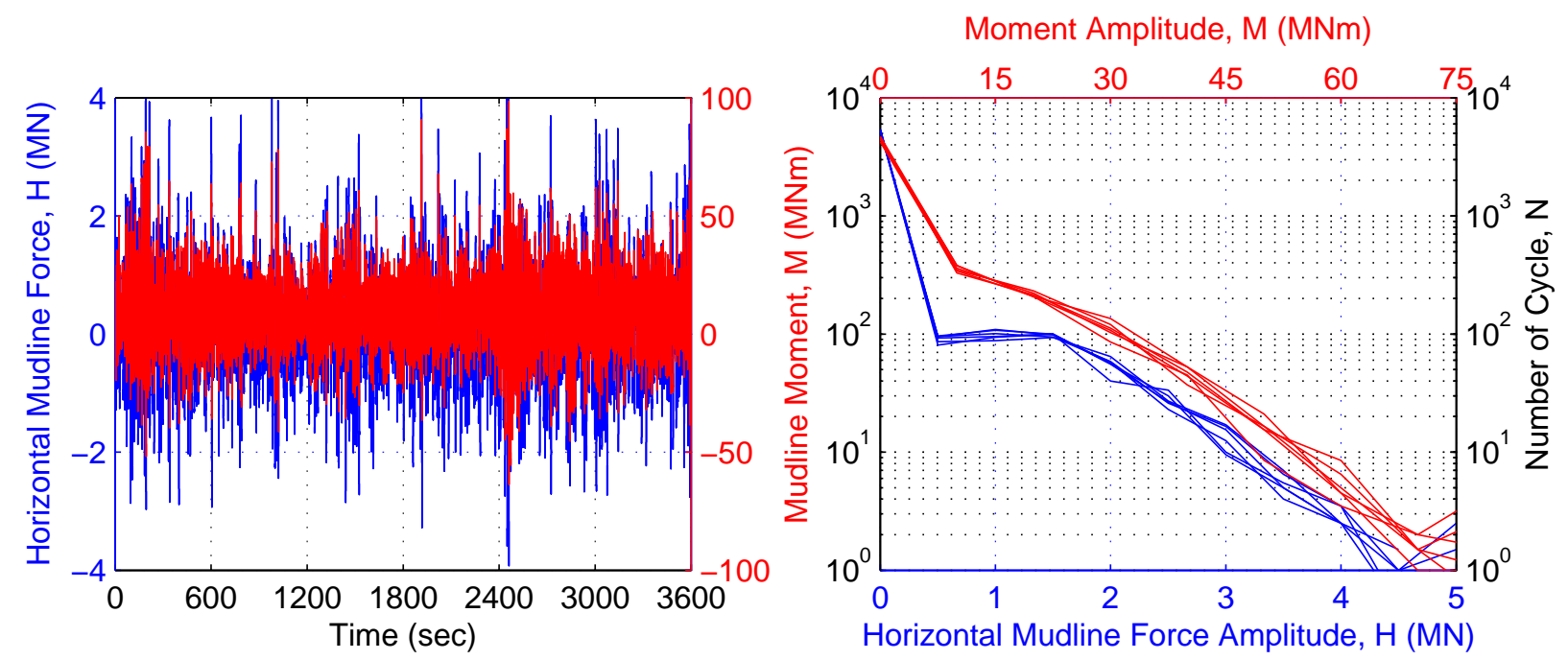
mudline force and moment from six random 1-hr storm load histories for 50-year (storm) MA site 
357 For degradation analysis it was necessary to idealize the storm time histories into load parcels of ( $H, M$,

$358 N$ ). Because rainflow counts for $H$ and $M$ are calculated separately and $H$ and $M$ are not perfectly 359 correlated, there is no precise way of linking $N$ to a simultaneous pair of $(H, M)$; consequently, a synthetic 360 rainflow count of $H$ was created deterministically as a function of $M$ using the relationship between $H$ and $361 M$ for the FAST time histories from each load scenario. For the storm-based 50-year MA time histories, 362 the average slope relating $H$ to $M$ is $1 / 0.0582$ with a correlation coefficent of 0.860 ; after determining the 363 rainflow count for $M$, a synthetic rainflow count for $H$ was created by using the number of cycles $N$ from 364 the moment count and by scaling $M$ by a factor of 0.0582 (Figure 9). While the synthetic rainflow count 365 overpredicts the number of cycles at lower amplitudes, the higher amplitude cycles influence degradation 366 results much more strongly than the lower amplitude cycles. Additionally, the magnitude of $M$ influences 367 results more strongly than $H$. The average correlation coefficient between $H$ and $M$ for the realizations of 368 the five storms ranged between 0.8 to 0.9 ; for storms with lower correlation coefficients, this synthetic 369 rainflow counting method would likely be too conservative. In cases where the moment and shear are 370 found to be only weakly correlated, a statistical approach could be implemented in which the shear cycle 371 amplitudes and counts are simulated conditional upon the moment cycle amplitudes and counts, or 372 althernatively, time history analysis of the foundation system would result in rainflow counts of the force 373 in each of the $p-y$ springs allowing direct modeling of the degradation of each $p-y$ spring without the need 374 to assume correlation between moment and shear. This second procedure would be significantly more 375 computationally intensive than the procedure presented here and is therefore left as a topic for future 376 study.

377 The average rainflow counts of the six realizations for each load scenario (Table 2) indicate that the 378 storm-based 50-year MA load scenario will lead to greater degradation of the ultimate soil resistance $p_{u}$ 379 and therefore to greater degradation of the OWT natural frequency and larger permanent accumulated 380 rotation. 

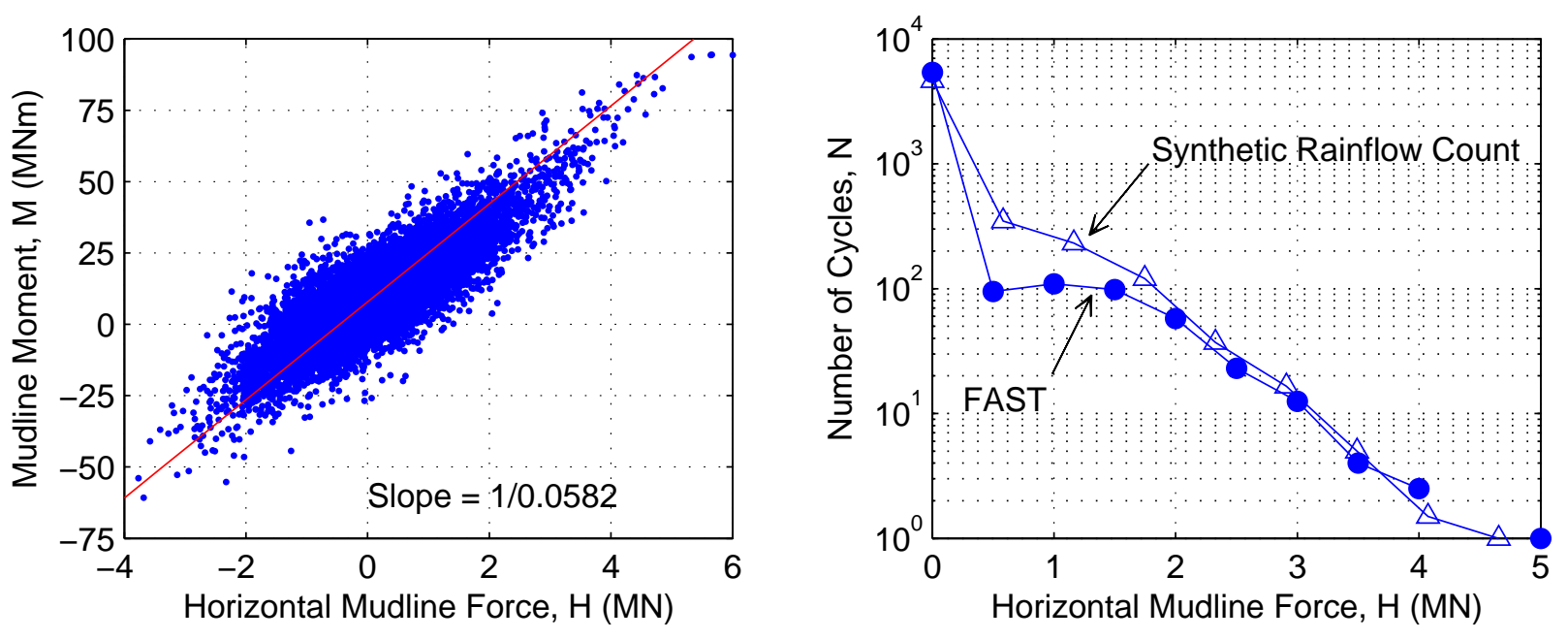

Figure 9 Example (A) Relationship between horizontal mudline force and mudline moment and (B) comparison of synthetic rainflow cycle count from mudline moment and horizontal mudline force from one realization of a 1-hr storm load history for 50-year (storm) MA site

Table 2 Average Rainflow Counts and Slope for the MA and DE Load Scenarios

\begin{tabular}{cccccc}
$\begin{array}{c}\text { Mudline } \\
\text { Moment } \\
\begin{array}{c}\text { Amplitude } \\
\text { (MNm) }\end{array}\end{array}$ & $\begin{array}{c}50 \text { years } \\
\text { Tropical } \\
\text { Storm }\end{array}$ & Me years & 500 years & 50 years & 500 years \\
\hline 0 & 4519 & 4394 & 3761 & 3454 & 4033 \\
10 & 357 & 344 & 359 & 431 & 435 \\
20 & 215 & 211 & 247 & 238 & 236 \\
30 & 111 & 100 & 93 & 52 & 45 \\
40 & 46 & 29 & 26 & 4.9 & 4.7 \\
50 & 16 & 8.4 & 4.3 & 0.2 & 0.3 \\
60 & 5.4 & 2.3 & 1.6 & 0 & 0 \\
70 & 1.6 & 0.6 & 0 & 0 & 0 \\
80 & 1.3 & 0.1 & 0 & 0 & 0 \\
90 & 0.3 & 0 & 0 & 0 & 0 \\
100 & 0.4 & 0 & 0 & 0 & 0 \\
\hline M/H slope (m) & $1 / 0.0582$ & $1 / 0.0605$ & $1 / 0.0536$ & $1 / 0.0470$ & $1 / 0.0491$
\end{tabular}

\subsection{Natural Frequency Degradation}

389 While calculating the natural frequency of the tower and RNA of an OWT is relatively straightforward,

390 including soil-structure interaction in the calculation requires several modeling assumptions due to the 
nonlinearity of soil-structure behavior and the requirement of linear springs in a natural frequency eigenvalue analysis. As mentioned in Section 3, two different estimates of initial stiffness can be used for clays (identified previously as $K_{0}$ and $K_{1}$ ); considering homogeneous deposits of clay with $s_{u}=35 \mathrm{kPa}, 50$ $\mathrm{kPa}$, and $100 \mathrm{kPa}$, Table 3 illustrates the slight $(<5 \%)$ variation in the estimation of the first natural frequency $f_{1}$ for the NREL $5 \mathrm{MW}$ as a function of initial stiffness, and approximately $7 \%$ difference in $f_{1}$ between the $s_{u}=35 \mathrm{kPa}$ and $s_{u}=100 \mathrm{kPa}$ clays.

Table 3 Estimations of the Initial First Natural Frequency $\left(f_{1}\right)$ for the NREL 5MW Reference Turbine

\begin{tabular}{cccc}
$\boldsymbol{s}_{\boldsymbol{u}}$ & $\boldsymbol{f}_{\mathbf{1}}\left(\boldsymbol{K}_{\boldsymbol{0}}\right)$ & $\boldsymbol{f}_{\mathbf{1}}\left(\boldsymbol{K}_{\mathbf{1}}\right)$ & $\begin{array}{c}\text { Reduction Causing } \boldsymbol{f}_{\boldsymbol{1}}< \\
\mathbf{1 P}(\mathbf{0 . 2 ~ H z})\end{array}$ \\
\hline $35 \mathrm{kPa}$ & $0.234 \mathrm{~Hz}$ & $0.245 \mathrm{~Hz}$ & $15-18 \%$ \\
$50 \mathrm{kPa}$ & $0.241 \mathrm{~Hz}$ & $0.250 \mathrm{~Hz}$ & $17-20 \%$ \\
$100 \mathrm{kPa}$ & $0.251 \mathrm{~Hz}$ & $0.257 \mathrm{~Hz}$ & $20-22 \%$
\end{tabular}

The 1P and 3P frequencies of the NREL 5MW are $0.2 \mathrm{~Hz}$ and $0.33 \mathrm{~Hz}$, respectively [16]. A natural frequency below the 1P frequency is a likely indication of a resonant condition, as (1) the frequency region below 1P is largely dominated by the wave frequency spectrum and (2) because natural frequency degradation is not a discrete process, and therefore the natural frequency must necessarily conflict with the $1 \mathrm{P}$ frequency before falling below $1 \mathrm{P}$.

The natural frequencies in Table 3 are only applicable for very small loads; for larger loads, the natural frequency of the OWT is determined by the secant stiffness of the $p-y$ springs (using the method described in Section 4). Using the average maximum loads from the six load scenarios in Table 1 and limiting the maximum stiffness of the springs to $K_{0}$, Table 4 compares the difference in large strain natural frequency estimation to initial natural frequency for cases including no embedment depth reduction, $0.5 b$ pile diameters of embedment reduction, one pile diameter $b$ of embedment reduction, and cumulative cyclic degradation. For the cumulative cyclic degradation case, the secant $p-y$ stiffness $K_{\text {sec }}$ was defined using the peak spring displacement from the final storm load parcel. Reductions in natural frequency marked with an asterisk indicate cases in which the natural frequency is below 1P.

Table 4 shows that the dominant load scenario for all analyses is the 50-year MA storm case. The higher magnitude of the MA loads had a more significant effect on natural frequency than the lower magnitude DE loads, resulting in natural frequencies below $1 \mathrm{P}$ for all of the $s_{u}=35 \mathrm{kPa}$ cases and for $s u=50 \mathrm{kPa}$ when considering $0.5 b$ to $1 b$ of embedment reduction. It is also interesting to note that the cumulative cyclic degradation method estimates higher natural frequencies (less reduction as compared to small strain estimates) when compared to the quasi-static $p-y$ method using average maximum loads. This is likely due to the fact that the average maximum loads are significantly larger than the maximum load 
cycles from rainflow counting, but in this case using a quasi-static $p-y$ method with average maximum loads is more conservative than the cumulative effect of a storm time history.

Table 4 Percent difference in first natural frequency from initial stiffness estimation $\left(K_{0}\right)$ for the average maximum mudline loads and average percent difference for the cumulative load effect from rainflow counts. Negligible changes in natural frequency are denoted as “_”.

\begin{tabular}{|c|c|c|c|c|c|c|}
\hline \multirow{3}{*}{\multicolumn{2}{|c|}{$\begin{array}{c}\text { Undrained Shear } \\
\text { Strength } \\
\left(s_{u}\right)\end{array}$}} & \multicolumn{3}{|c|}{ MA } & \multicolumn{2}{|c|}{ DE } \\
\hline & & \multirow{3}{*}{$\begin{array}{c}\begin{array}{c}50 \text { years } \\
\text { Tropical Storm }\end{array} \\
-28 \% *\end{array}$} & \multirow{3}{*}{$\begin{array}{l}50 \text { years } \\
\text { Measured } \\
-7.1 \%\end{array}$} & \multirow{3}{*}{$\begin{array}{c}500 \text { years } \\
\text { Measured } \\
-13 \%\end{array}$} & \multirow{3}{*}{$\begin{array}{c}50 \text { years } \\
\text { Measured } \\
-1.5 \%\end{array}$} & \multirow{3}{*}{$\begin{array}{c}500 \text { years } \\
\text { Measured } \\
-1.7 \%\end{array}$} \\
\hline & & & & & & \\
\hline No & $35 \mathrm{kPa}$ & & & & & \\
\hline \multirow{2}{*}{$\begin{array}{l}\text { Embedment } \\
\text { Reduction }\end{array}$} & $50 \mathrm{kPa}$ & $-14 \%$ & $-2.5 \%$ & $-4.4 \%$ & $-0.2 \%$ & $-0.3 \%$ \\
\hline & $100 \mathrm{kPa}$ & $-2.6 \%$ & $-0.2 \%$ & $-0.7 \%$ & - & - \\
\hline \multirow{3}{*}{$\begin{array}{c}0.5 b \\
\text { Embedment } \\
\text { Reduction }\end{array}$} & $35 \mathrm{kPa}$ & $-35 \% *$ & $-12 \%$ & $-18 \% *$ & $-3.2 \%$ & $-3.6 \%$ \\
\hline & $50 \mathrm{kPa}$ & $-20 \% *$ & $-4.5 \%$ & $-7.8 \%$ & $-1.0 \%$ & $-1.2 \%$ \\
\hline & $100 \mathrm{kPa}$ & $-4.4 \%$ & $-0.8 \%$ & $-1.6 \%$ & - & - \\
\hline \multirow{3}{*}{$\begin{array}{c}1 b \\
\text { Embedment } \\
\text { Reduction }\end{array}$} & $35 \mathrm{kPa}$ & $-45 \% *$ & $-19 \% *$ & $-26 \% *$ & $-6.7 \%$ & $-7.4 \%$ \\
\hline & $50 \mathrm{kPa}$ & $-28 \% *$ & $-8.6 \%$ & $-14 \%$ & $-2.7 \%$ & $-3.0 \%$ \\
\hline & $100 \mathrm{kPa}$ & $-8.0 \%$ & $-2.0 \%$ & $-3.1 \%$ & $-0.4 \%$ & $-0.5 \%$ \\
\hline \multirow{3}{*}{$\begin{array}{c}\text { Cumulative } \\
\text { Load } \\
\text { Effect }\end{array}$} & $35 \mathrm{kPa}$ & $-24 \% *$ & $-6.0 \%$ & $-12 \%$ & $-0.8 \%$ & $-1.1 \%$ \\
\hline & $50 \mathrm{kPa}$ & $-9.3 \%$ & $-2.0 \%$ & $-4.0 \%$ & $-0.2 \%$ & $-0.3 \%$ \\
\hline & $100 \mathrm{kPa}$ & $-1.5 \%$ & $<0.1 \%$ & $-0.5 \%$ & $<0.1 \%$ & $<0.1 \%$ \\
\hline
\end{tabular}

$424 *$ denotes cases in which the degraded natural frequency is below $1 \mathrm{P}$.

\subsection{Estimation of Permanent Accumulated Mudline Rotation}

As previously proposed, permanent inelastic soil deformation is assumed to occur when $p-y$ springs are mobilized beyond $p / p_{u}=0.5 ; p-y$ springs for which $p / p_{u}<0.5$ are assumed to behave elastically. In order to broadly measure the severity of the storm loading conditions above, the quasi-static average maximum mudline loads $H_{\max , a v g}$ and $M_{\max , a v g}$ from the most severe storm case (storm-based 50-year MA) were used to determine the degree of mobilization (i.e., the ratio of demand $p$ vs. ultimate resistance $p_{u}$ ) for $p-y$ spring-supported monopiles embedded in homogeneous clay deposits of $s_{u}=100 \mathrm{kPa}, 50 \mathrm{kPa}$, and $35 \mathrm{kPa}$ (Figure 10). The soil springs are assumed to be symmetric, thus Figure 10 demonstrates the degree of $p-y$ mobilization in terms of the absolute value of $p$. 


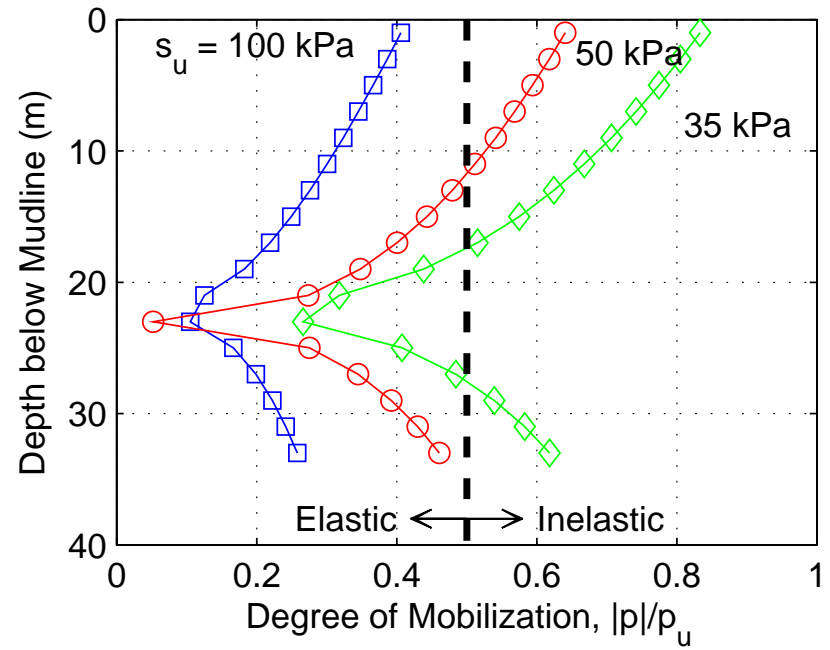

Figure 10 Degree of $p-y$ mobilization for undrained shear strengths of 100, 50, and $25 \mathrm{kPa}$ considering average maximum loads from six random 1-hr storm load histories for 50-year (Tropical Storm) MA site

For the monopile in stiff clay $\left(s_{u}=100 \mathrm{kPa}\right)$, even the most severe loading conditions from Table 1 do not push the soil beyond the elastic range. For the pile in medium (50 kPa) clay, the soil at approximately the top third of the pile exceeds the elastic range, and for the soft (35 kPa) clay the majority of the soil behaves inelastically. The influence of inelastic soil behavior is further demonstrated by the load-unload paths of the pile head for these three cases in Figure 11, where no permanent accumulated rotation can be seen for the $100 \mathrm{kPa}$ case, a very small amount of permanent accumulated rotation for the $50 \mathrm{kPa}$ case, and an exceedance of the $0.25^{\circ}$ permanent mudline rotation SLS for the $35 \mathrm{kPa}$ case.

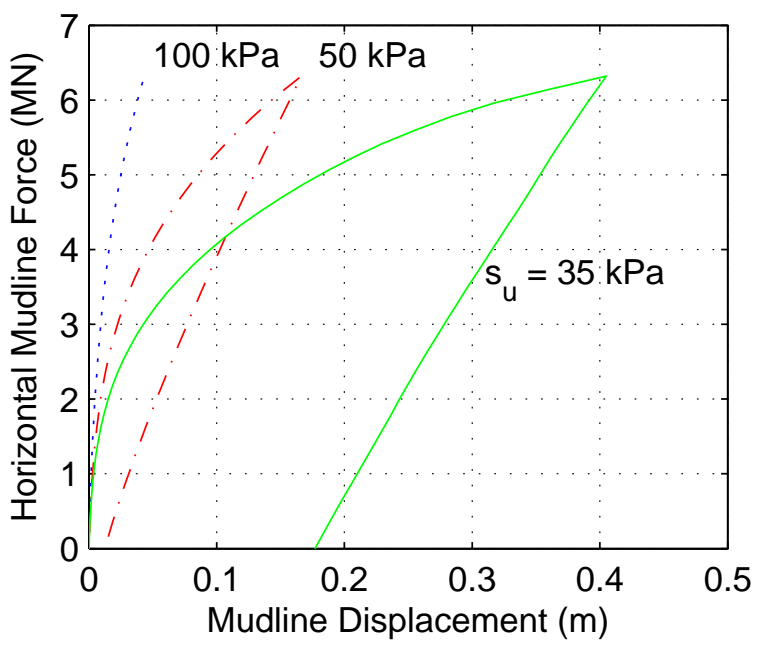

(A)

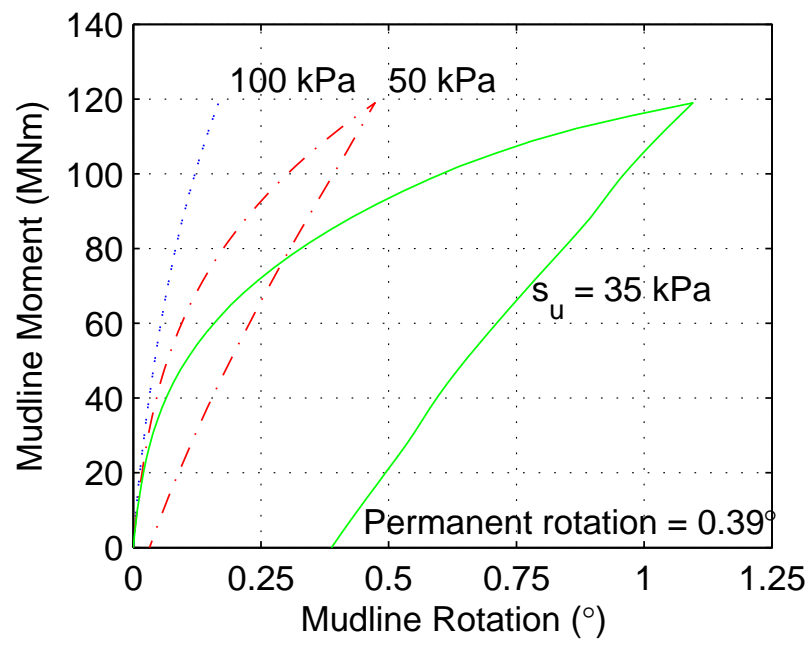

(B)

Figure 11 (A) Force-displacement and (B) Moment-rotation load-unload path for undrained shear strengths of 100, 50, and $25 \mathrm{kPa}$ considering average maximum loads from six random 1-hr storm load histories for 50-year

(Tropical Storm) MA site 
As in the prior section, the permanent accumulated rotation from the average maximum load cases was compared with the cumulative cyclic degradation method (Table 5). Permanent rotations less than $0.01^{\circ}$ were considered to be negligible (denoted as "-" in Table 5). The results from the embedment reduction cases of $0.5 b$ and $1 b$ show significantly more permanent rotation than the cumulative cyclic degradation

454 method for the 50-year MA (tropical storm) case; considering a monopile in $s_{u}=35 \mathrm{kPa}$ clay, the removal 455 of $p-y$ springs prior to applying the 50-year MA tropical storm loads exceeded the capacity of the pile for 456 both $0.5 b$ and $1 b$ amounts of embedment reduction. It should also be noted however that the average 457 maximum mudline loads used in the embedment reduction cases exceeds the magnitude of the highest 458 cycles obtained from rainflow counting; as such, the results in Table 5 are also representative of the effect 459 of load magnitude on the estimation of permanent accumulated rotation.

Table 5 Permanent accumulated rotation for the average maximum mudline loads and average percent difference for the cumulative load effect from rainflow counts. Rotations denoted as “-” are negligible.

\begin{tabular}{ccccccc}
\multicolumn{2}{c}{$\begin{array}{c}\text { Undrained Shear } \\
\text { Strength } \\
\left(\boldsymbol{s}_{\mathbf{u}}\right)\end{array}$} & $\begin{array}{c}\text { MA } \\
50 \text { years } \\
\text { Tropical Storm }\end{array}$ & $\begin{array}{c}50 \text { years } \\
\text { Measured }\end{array}$ & $\begin{array}{c}500 \text { years } \\
\text { Measured }\end{array}$ & $\begin{array}{c}50 \text { years } \\
\text { Measured }\end{array}$ & $\begin{array}{c}500 \text { years } \\
\text { Measured }\end{array}$ \\
\hline No & $35 \mathrm{kPa}$ & $0.39^{\circ}$ & - & - & - & - \\
Embedment & $50 \mathrm{kPa}$ & $0.03^{\circ}$ & - & - & - & - \\
Reduction & $100 \mathrm{kPa}$ & - & - & - & - & - \\
\hline $0.5 b$ & $35 \mathrm{kPa}$ & failure & - & $0.05^{\circ}$ & - & - \\
Embedment & $50 \mathrm{kPa}$ & $0.20^{\circ}$ & - & - & - & - \\
Reduction & $100 \mathrm{kPa}$ & - & - & - & - & - \\
\hline $1 b$ & $35 \mathrm{kPa}$ & failure & $0.01^{\circ}$ & $0.15^{\circ}$ & - & - \\
Embedment & $50 \mathrm{kPa}$ & $0.58^{\circ}$ & - & - & - & - \\
Reduction & $100 \mathrm{kPa}$ & - & - & - & - & - \\
\hline Cumulative & $35 \mathrm{kPa}$ & $0.15^{\circ}$ & - & $0.01^{\circ}$ & - & - \\
Load & $50 \mathrm{kPa}$ & $0.01^{\circ}$ & - & - & - & - \\
Effect & $100 \mathrm{kPa}$ & - & - & - & - & -
\end{tabular}

462 Figure 12 compares the cumulative cyclic degradation force-displacement paths considering monopiles in 463 clays with $s_{u}=35 \mathrm{kPa}, 50 \mathrm{kPa}$, and $100 \mathrm{kPa}$. The monopile in $100 \mathrm{kPa}$ clay does not sustain any 464 significant cyclic degradation, which is expected given the results of the natural frequency study. For the 465 monopile in $50 \mathrm{kPa}$ clay, only the largest amplitude cycles induce inelastic soil behavior. Both cyclic 466 degradation and highly inelastic behavior are present for the monopile in $35 \mathrm{kPa}$ clay, with cyclic degradation clearly demonstrated between the ultimate and penultimate load parcels. 


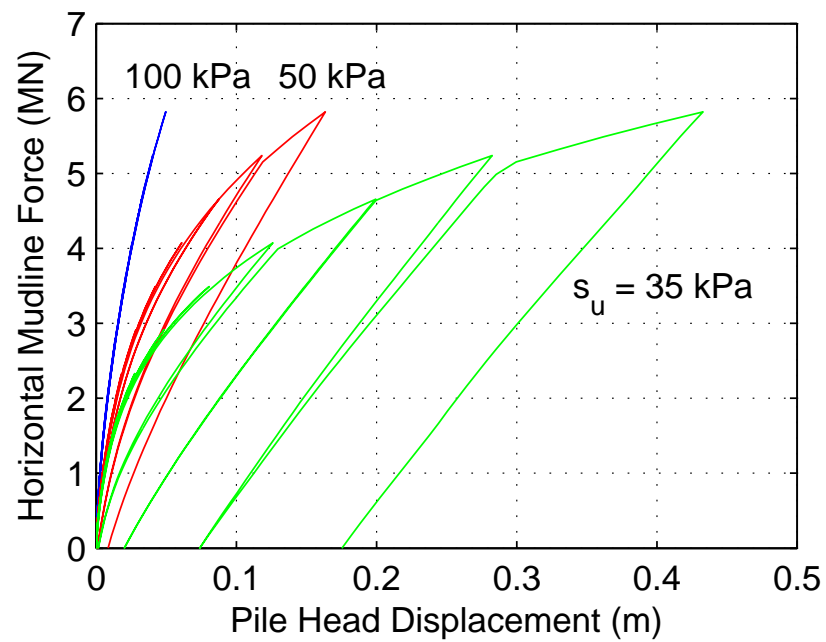

Figure 12 Example force-displacement load-unload path of pile head for cumulative load effect from 1-hr storm load history for 50-year (storm) MA site

\section{Conclusions}

Monopiles are the predominant foundation type for offshore wind turbines (OWTs) and are typically designed using the $p-y$ method to model lateral soil behavior. The $p-y$ method is relatively simple and easy to implement, making it a convenient alternative to finite element models; however, an important drawback when applied to OWT monopiles is that $p-y$ models assume flexible pile behavior and have limited ability to model cyclic effects and permanent accumulated rotation after loading. This paper presents two options for how cyclic degradation may be taken into account (via cumulative cyclic $p-y$ degradation and quasi-static $p-y$ methods with embedment reduction) and how to estimate permanent accumulated mudline rotation for OWT monopiles in clay. The assumptions inherent in the $p-y$ curve formulation necessitate experimental validation of the degradation and permanent accumulated rotation methods presented here for large diameter monopiles. It should be noted that this paper assumed the same embedment depth for the monopile supporting the NREL 5MW Reference Turbine (NREL 5MW) [16] in soft, medium, and stiff clays, and a full examination of appropriate embedment depth (such as the one performed by [21], e.g.) and monopile design may change the results presented here. The objective of this paper was to present an illustrative example of the range of degradation behavior from the two different cyclic degradation methods. One hour time histories of extreme storm loading (with turbulent winds and irregular waves) were assessed in FAST [17] for two sites off the coast of Massachusetts (MA) and Delaware (DE), considering mean return periods from 50 to 500 years. For each load scenario, six different random time histories were generated, and rainflow counts of the mudline moment $M$ were assessed. For the cumulative cyclic degradation analysis, it was necessary to parcel mudline loading into a simultaneous pair of horizontal mudline force $H$ and $M$ associated with a certain number of cycles; 
consequently, a synthetic rainflow count of $H$ was produced from the rainflow count of $M$ using a sitespecific coefficient determined from the relationship between $H$ and $M$ from the FAST time histories.

494 The natural frequency of the NREL 5MW was examined for monopiles in homogeneous clay deposits with undrained shear strength $s_{u}=35 \mathrm{kPa}, 50 \mathrm{kPa}$, and $100 \mathrm{kPa}$ (representing soft, medium, and stiff clays respectively) to demonstrate a range of clay behavior subjected to extreme loading. Because the $p-y$ curve formulation by [14] has infinite initial stiffness, the estimates of initial natural frequency from DNV [9] were compared. Using the average maximum load from each load scenario, the natural frequency calculated from the secant stiffness of the $p$-y springs was also examined. Using the quasi-static average maximum load to estimate natural frequency was more conservative than using the cumulative cyclic degradation method.

The serviceability limit state (SLS) imposed on OWT monopiles requires the designer to assess the accumulated permanent pile rotation after storm loading to ensure that the mudline rotation does not exceed a threshold magnitude (typically on the order of $0.25^{\circ}$ ). Design guidelines do not recommend a specific method for determining this permanent residual rotation [9], and consequently some designers conservatively choose to design piles which do not exceed the SLS at peak loading. This paper uses the cyclic unload-reload modulus proposed in [14], assuming that $p-y$ springs behave elastically if loaded at or below half of the ultimate resistance $p_{u}$ at spring depth. Using the average maximum load from the storm-based 50-year MA loads, the monopile in $100 \mathrm{kPa}$ clay remained fully elastic (all springs were loaded $<0.5 p_{u}$ ), partially inelastic for the $50 \mathrm{kPa}$ clay, and almost fully plastic for the $35 \mathrm{kPa}$ clay (nearly 511 all springs loaded $>0.5 p_{u}$ ).

512 The conclusions of this paper indicate that extreme storm loading on OWT monopiles in stiff clays is 513 unlikely to affect the natural frequency and permanent accumulated rotation; further consideration is 514 required for OWT monopiles in medium clays, as storm load estimation and the number of storms 515 experienced by the monopile during the design lifetime may affect future performance. Under the same 516 design conditions, the monopile in soft clay is insufficient with respect to both natural frequency 517 degradation and permanent rotation. The results of this paper also indicate that load magnitude plays a 518 strong role in both natural frequency and permanent rotation estimation, so using average maximum loads 519 from storm time histories was more conservative than using a cumulative cyclic degradation model. The 520 influence of cyclic load magnitude on permanent accumulate rotation is supported by the conclusions 521 presented in [33] from centrifuge testing on a cyclically-loaded monopile in clays of $s_{u}=25 \mathrm{kPa}$ to 100 $522 \mathrm{kPa}$. 
Validation of these approaches by experimental or high fidelity (3D nonlinear finite element) numerical analysis is needed to allow incorporation of foundation response to extreme loads cyclic loads into design and risk assessment procedures. It is hoped that the methods and results presented here can provide guidance to experimentalists interested in designing and executing experimental programs to investigate performance of monopile foundations in clay during storms. Moreover, a complete parametric study of the range of possible monopile designs, soil conditions, and environmental conditions broadly reflective of the US Atlantic Coast would be a valuable extension to this study, which was focused on explication of methods for analysis of monopile response under extreme cyclic loads. The authors intend to engage in such a study based on other parametric studies of OWT design [34].

\section{Acknowledgements}

The research was supported by the grants CMMI-1234560, CMMI-1234656, the Massachusetts Clean Energy Center and the NSF-sponsored IGERT: Offshore Wind Energy Engineering, Environmental Science, and Policy (Grant Number 1068864).

\section{References}

[1] Hamilton, B., Battenberg, L., Bielecki, M., Bloch, C., Decker, T., Frantzis, L., Paidipati, J., Wickless, A., and Zhao, F., 2013, Offshore Wind Market and Economic Analysis: Annual Market Assessment, Navigant Consulting, Inc., Burlington, MA.

[2] Dolores Esteban, M., López-Gutiérrez, J.-S., Negro, V., Matutano, C., García-Flores, F. M., and Millán, M. Á., 2015, “Offshore Wind Foundation Design: Some Key Issues,” J. Energy Resour. Technol., 137(5), p. 050801.

[3] Andersen, K. H., 2009, "Bearing capacity under cyclic loading - offshore, along the coast, and on land. The 21st Bjerrum Lecture presented in Oslo, 23 November 2007," Can. Geotech. J., 46(5), pp. 513-535.

[4] Andersen, K., 1976, "Behaviour of clay subjected to undrained cyclic loading," Proc. International Conference on the Behavior of Offshore Structures, Trondheim, Norway, pp. 33-44.

[5] Gerolymos, N., and Gazetas, G., 2005, "Phenomenological model applied to inelastic response of soil-pile interaction systems," Soils Found., 45(4), pp. 119-132.

[6] Heidari, M., Jahanandish, M., El Naggar, H., and Ghahramani, A., 2014, "Nonlinear cyclic behavior of laterally loaded pile in cohesive soil," Can. Geotech. J., 51, pp. 129-143.

[7] Dunnavant, T. W., and O’Neill, M. W., 1989, "Experimental p-y Model for Submerged, Stiff Clay," J. Geotech. Eng., 115, pp. 95-114.

[8] Pranjoto, S., and Pender, M., 2003, "Gapping effects on the lateral stiffness of piles in cohesive soil," Proc. Pacific Conf. Earthq. Eng.

[9] DNV, 2013, DNV-OS-J101 Design of Offshore Wind Turbine Structures, Det Norske Veritas AS.

[10] Klinkvort, R. T., Leth, C. T., and Hededal, O., 2010, "Centrifuge modelling of a laterally cyclic 
loaded pile," International Conference on Physical Modelling in Geotechnics, Taylor \& Francis Group, Zurich, Switzerland, pp. 959-964.

[11] Hamre, L., Khankandi, S. F., Strøm, P. J., and Athanasiu, C., 2011, "Lateral behaviour of large diameter monopiles at Sheringham Shoal Wind Farm," Frontiers in Offshore Geotechnics II, pp. $575-580$.

[12] Martínez-Chaluisant, V., 2011, "Static and Dynamic Response of Monopiles for Offshore Wind Turbines," University of Wisconsin-Madison.

[13] Hokmabadi, A. S., Fakher, A., and Fatahi, B., 2012, "Full scale lateral behaviour of monopiles in granular marine soils," Mar. Struct., 29(1), pp. 198-210.

[14] Matlock, H., 1970, "Correlations for design of laterally loaded piles in soft clay," Offshore Technology Conference, Dallas, TX.

[15] Rajashree, S. S., and Sundaravadivelu, R., 1996, "Degradation model for one-way cyclic lateral load on piles in soft clay," Comput. Geotech., 19(4), pp. 289-300.

[16] Jonkman, J., Butterfield, S., Musial, W., and Scott, G., 2009, Definition of a 5-MW Reference Wind Turbine for Offshore System Development.

[17] Jonkman, J., and Buhl, M. J., 2005, FAST User's Guide, National Renewable Energy Laboratory, Golden, CO.

[18] Reese, L., Cox, W., and Koop, F., 1975, "Field Testing and Analysis of Laterally Loaded Piles in Stiff Clay," Offshore Technol. Conf.

[19] American Petroleum Institute, 2005, “API RP-2A.”

[20] Carswell, W., Fontana, C., Degroot, D. J., and Myers, A. T., 2015, “Comparison of Cyclic p-y Curves for Offshore Wind Turbine Monopiles Subjected to Extreme Storm Loading," Proceedings of the ASME 2015 34th International Conference on Ocean, Offshore, and Arctic Engineering (OMAE2015), St. Johns, Newfoundland, Canada.

[21] de Vries, W., and Krolis, V., 2007, "Effects of deep water on monopile support structures for offshore wind turbines," European Wind Energy Conference \& Exhibition (EWEC), Milan, pp. 110 .

[22] Shin, Y., Saue, M., Langford, T., Petter, H., Cho, K., and Park, J., 2014, "Pile-Soil Interaction under Cyclic Loadings for Offshore Wind Monopiles," Proceedings of the ASME 2014 33rd International Conference on Ocean, offshore, and Arctic Engineering (OMAE2014), pp. 1-8.

[23] Lombardi, D., Bhattacharya, S., and Muir Wood, D., 2013, "Dynamic soil-structure interaction of monopile supported wind turbines in cohesive soil," Soil Dyn. Earthq. Eng., 49, pp. 165-180.

[24] Boulanger, B. R. W., Curras, C. J., Kutter, B. L., Wilson, D. W., and Abghari, A., 1999, "Seismic Soil-pile-strcture interaction experiments and analysis," J. Geotech. Geoenvironmental Eng., 125(September), pp. 750-759.

[25] Negro, V., López-Gutiérrez, J.-S., Esteban, M. D., and Matutano, C., 2014, "Uncertainties in the design of support structures and foundations for offshore wind turbines," Renew. Energy, 63, pp. $125-132$.

[26] Lesny, K., Paikowsky, S., and Gurbuz, A., 2007, "Scale effects in lateral load response of large diameter monopiles,” Proc. Sess. Geo-Denver 2007 Contemp. Issues Deep Found., (158).

[27] Stansby, P. K., Stallard, T. J., and Devaney, L. C., 2013, "Breaking wave loads on monopiles for offshore wind turbines and estimation of extreme overturning moment," IET Renew. Power Gener., 7(5), pp. 514-520.

[28] Damgaard, M., Bayat, M., Andersen, L. V., and Ibsen, L. B., 2014, “Assessment of the dynamic 
602

603

604 [29] MMI Engineering, 2009, Comparative Study of OWTG Standards: Prepared for JIP Sponsorship.

605 [30] National Oceanic and Atmospheric Administration, 2014, "National Data Buoy Center."

606 [31] Valamanesh, V., Myers, A. T., and Arwade, S. R., 2015, "Multivariate analysis of extreme 607

608

609

610

611

612

613

behaviour of saturated soil subjected to cyclic loading from offshore monopile wind turbine foundations," Comput. Geotech., 61, pp. 116-126. metocean conditions for offshore wind turbines," Struct. Saf., 55, pp. 60-69.

[32] IEC 61400-3, 2009, Design Requirements for Offshore Wind Turbines, Brussels.

[33] Haigh, S. K., 2014, "Foundations for offshore wind turbines.," 8th International Conference on Physical Modeling in Geotechnics, at Perth.

[34] Myers, A. T., Arwade, S. R., Valamanesh, V., and Hallowell, S., 2015, "Strength, Stiffness, Resonance and the Design of Offshore Wind Turbine Monopiles," Eng. Struct., 100, pp. 332-341. 